sum facere, quin uno verbo dicam quam gratum mihi fuerit vidisse, etiam a Kirchnero p. 43 scholiastam illum, quem putabant, Aemilium prorsus fictum ac nullum esse probari. Idem iam ante sex annos evincere studui in Hoiatianorum partic. I. Aquisgrani conseripta p. 8; idem nuper ostendit Hauthalius, vir doctissimus, in Museo Rhenano a.1846.p. 516 sqq.; hic quidem nova ratione; Kirchnerus in id ipsum incidit, quod ego iam tum proposui. Sed haec hactenus.

Embricae a. d. V. Kal. Nov. MDCCCXLVII.

\title{
EX PRAEFATIONE
}

EDITIONIS III.

In emendandam novam editionem Horatii mei quantam per labores officiumque licuit curam impendi; rationem naturamque libri ne nunc quidem mutavi. Nam quanquam non defuerunt qui consulenti mihi persuadere vellent, ut commentario argumentisque singulorum carminum decurtatis vel mutilatis librum contraherem in angustumque deducerem, tamen metui, si illorum vocibus auscultarem, ne minuerem simul vel demerem potius si quid esset vel probabile vel peculiare. Scio quidem, inter magistros scholarum publicarum esse aliquos, qui editiones commentariis instructas a suis lectionibus prohibeant nudaque poetae verba discipulorum manibus tradant. Quorum studium voluntatemque tantum abest ut reprebendere audeam, ut magnopere laudem, siquidem in ipsis lectionibus id 
possint assequi, ut viva voce doctrinaeque cura et diligentia ea omnia, quae ad veram carminum intellegentiam necessaria sunt, adulescentulorum animis ipsi praebeant memoriaeque infigant. Illud tamen metuendum est, ne ista lectio iusto saepius aut habeat aliquid vagum et incertum aut parvam tantum dulcissimi poetae partem comprehendat. Iis autem, qui commentarios ob eam causam prohibent, ne adulescentium celeritate acieque oculorum et calliditate ingeniorum inter docendum et explorandum quasi quaedam insidiae sibi struantur, optime olim Frid. Iacobsius, nuper Kruegerus in praefat. edit. sermonum p. IV occurrit. Praeterea cum ne summa quidem assiduitas vel magistrorum vel discipulorum eo possit pervenire, ut omnia legantur quae lectu dignissima sint, non potest fieri quin privatis studiis bona pars poematum relinquatur; quae si vult intellegi, adiumenta requirit non parca aut debilia, sed ad superandas difficultates et parata semper et firma. Deinde si licet sperare, fore ut iuventus tantopere blanditiis poetae capiatur, ut etiam relictis ludis et virili aetate ad eius lectionem sua sponte ac libenter recurrat, ubertas argumentorum adnotationumque satis habere videtur non excusationis sed necessitatis.

Editiones commentationesque, quae interim prodiørunt quaeque ad me pervenerunt, legi ex iisque quaecumque meis meliora videbantur in meum usum converti. Fructus autem quem inde cepi, minor fuit quam exspectaveram*).

*) Iuvat commemorare etiam editionem, quae hoc titulo ornata prodiit: Horatii carmina quae exstant omnia. Iuxta editiones Doering, Orellii et Lipsianam accurate recensita. Oxonii: I. Abrams. Londini : William Allan. 1849. Quae cum nescio qualem textum praeberet, Horatii vitam et indicem metrorum ex mea editione clam sibi surripuit. 
Codicum scripturas scholiastasque denuo diligenter consului et examinavi; quo factum est, ut antiquissimorum librorum Mss., maxime Blandiniorum Cruquii, auctoritate lectiones in prima et altera editione receptas nunc cogerer mutare. Quod quam saepe necessarium visum sit ut intellegatur, locos ipsos nunc addam: ('arm. I, 7, 17. I, 8, 2. I, 15, 22. I, 19, 2. I, 24, 13*). I, 25, 2. III, 4, 31. III, 15, 16. III, 20, 8. IV, 4, 73. C. S. 68. 71. 72. Sat. I, 3,57 . I, 4, 87. I, 6,31 . I, 7, 50. II, $\cdot 1$, 31. II, 2,48 . II, 2, 56. II, 2, 95. II, 3,96 . II, 3,129 . II, 3,170 . II, 3,212 . II, 3,276 . II, 4,47 . II, 6,4 . II, 6,44 . II, 6, 48. II, 8, 52. II, 8, 53. Epist. I, 1, 72. I, 2, 38. I, 3, 30. I, 13, 2. I, 15, 10. I, 16, 22. 1, 18, 111. I, 19, 22. 23. II, 1, 69. II, 1, 85 (A. P. 161). II, 1, 167. II, 1, 186. II, 2,16 . II, 2,158 .

Regimontii Borussorum a.d.XIII. Kal. Mai MDCCCLIV.

\section{PRA E F A I O EDITIONIS IV.}

Quam abhinc annos prope sex aequitati doctorum hominum commendavi editionem tertiam, eius exempla cum essent divendita, institit redemptor egregius, ut quartum emitteretur libellus. Quod ut honeste fieret, denuo consului varietatem optimorum codicum, praecipue Blandiniorum C'ruquii, antiquorum Bentleii et

*) De hoc loco ef. Quaestiones meas Horatianas (Bonnae. Habicht 1841.) p. 48 sqq. 